\title{
Does a Role Exist for Tilting-Guided Therapy in the Management of Neurocardiogenic Syncope?
}

\author{
Denise Hachul, Mauricio Scanavacca, Eduardo Sosa \\ São Paulo, SP - Brazil
}

\begin{abstract}
Purpose - Upright tilt-table testing (UTT) is an useful method for identifying patients with neurocardiogenic syncope, but its role in the evaluation of therapeutic efficacy is controversial. The aim of this study was to determine the correlation between negative UTT after therapy introduction (acute efficacy) and symptom recurrence during follow-up (chronic efficacy).
\end{abstract}

Methods - We studied 56 severely symptomatic patients (age $27 \pm 19$ years) with recurrent $(7 \pm 12$ episodes) neurocardiogenic syncope (positive UTT). Once empirical pharmacological therapy was initiated, all patients underwent another UTT (therapeutic evaluation test TET). Therapy was not modified after TETresults. The probability of symptom recurrence was analyzed with the Kaplan-Meier method and compared by log-rank test in patients with negative and positive TET.

Results -Negative UTT after therapy was related to a significantly lower probability of recurrence during follow-up (4.9 versus $52.4 \%$ in 12 months, $P<0.0001$ ).

Conclusion - A good correlation exists between acute and long-term efficacy of pharmacological therapy for neurocardiogenic syncope, so that serial UTT may be considered a good method for identifying an effective therapeutic strategy.

Key words: tilt-table test, therapy, neurocardiogenic syncope

Heart Institute of São Paulo University - São Paulo - Brazil

Mailing address: Denise Hachul - Heart Institute of São Paulo University Arrhythmia Unit - Av. Dr. Enéas C. Aguiar, 44 - 05403-900 - São Paulo, SP - Brazil

- E-mail: dhachul@incor.usp.br

Received for publication on $21 / 3 / 01$

Accepted 20/6/01
Clinical features of neurocardiogenic syncope are highly variable ${ }^{1}$. A relevant aspect of this disorder is that syncope may be sporadic with long asymptomatic periods between episodes. Multiple recurrences are not uncommon, however, they have a great impact on lifestyle, and social and professional life ${ }^{2-4}$.

Management of neurocardiogenic syncope can be accomplished both pharmacologically and nonpharmacologically ${ }^{5-7}$. A specific treatment is usually recommended for patients with frequent recurrences. In case of a short prodromic period, high-risk professional activities or physical injury, treatment is recommended even after an isolated event. One of the main problems in managing neurocardiogenic syncope is establishing the real efficacy of medical treatment. Although the usefulness of upright tilt-table testing (UTT) in evaluating syncope is well established, its value as a predictor of therapeutic efficacy is still controversial ${ }^{7-13}$. Some authors consider a negative UTT after drug therapy as a mark of the acute efficacy of treatment. However, clinical studies assessing short- and long-term outcome in these patients are limited and have conflicting results ${ }^{13,14}$. Studies evaluating immediate and long-term reproducibility of the test have demonstrated that concordance between 2 positive tests is lower than between 2 negative tests ${ }^{15-23}$.

The objective of this study was to assess the correlation between UTT results-performed after the introduction of therapy (acute efficacy) and symptom recurrence during follow-up (chronic efficacy) in patients with recurrent neurocardiogenic syncope.

\section{Methods}

From August 1991 to November 1997, we prospectively studied 56 patients diagnosed with recurrent neurocardiogenic syncope (positive UTT). The criteria for inclusion in the study was a clinical history of 2 or more episodes of syncope or 1 syncope plus 3 or more near-syncope episodes during the year prior to UTT. Near-syncope was defined as the imminent sensation of loss of consciousness and loss of postural tone. 
The physical examination and noninvasive tests, such as 12-lead electrocardiography, 24-hour ambulatory Holter monitoring, and echocardiography disclosed negative findings ${ }^{15-17}$. Patients' mean age was $27 \pm 19$ years (ranging from 6 to 70 years) and 30 were female. Time elapsed from the first episode of syncope and UTT was $32 \pm 45$ months (ranging from 1 week to 22 years, median 12 months). Mean number of total episodes of syncope was $7 \pm 12$ (median of 4 episodes) with a mean of $4 \pm 3$ occurring during the year prior to admission (median of 3 episodes).

Upright tilt-table testing protocol - UTT - was performed in the morning, with patients in a fasting state. Patients were placed into a supine position on a tilt-table (Carci Industry, SP, Brazil). Blood pressure (BP) was continuously and noninvasively measured with a digital monitor (Finapress 2300 - Ohmeda) and a continuous electrocardiogram (ECG) was acquired by an ECG system (Hewlett-Packard) connected to the BP monitor. After the patients had been lying in a supine position for 20 minutes, they were tilted upright at a 60-degree angle and observed for 40 minutes or until syncope or near-syncope occurred. In that case, the table was replaced in the supine position (or Trendelenburg, if recovery was not achieved). No other intervention was necessary to control symptoms.

According to BP and HR changes, positive UTT responses were defined as: (1) vasodepressor response: decrease in systolic blood pressure of at least $30 \mathrm{mmHg}$ without significant changes in heart rate; (2) cardioinhibitory response: sudden asystolic periods of more than 3 seconds associated with hypotension; (3) mixed response: decrease in systolic blood pressure of $30 \mathrm{mmHg}$ or more, associated with bradycardia.

Study design: all patients were empirically and in a nonrandomized way treated with b-blocker (propranolol -1 $\mathrm{mg} / \mathrm{kg}$ daily) or fludrocortisone (Florinef $-1 \mu \mathrm{g} / \mathrm{kg}$ daily, up to a maximum of $200 \mu \mathrm{g}$ daily for adults).

Between 15 days and 1 month after drug therapy introduction, another UTT was performed (therapeutic evaluation test - TET). In case of recurrence, patients were asked to return for clinical evaluation without delay. Drugs were not modified according to the result of the TET. This was only done in case of recurrence of symptoms or drug intolerance, when therapy was empirically modified by increasing the dosage, replacing it, or adding another drug, such as disopyramide ( 200 to $400 \mathrm{mg}$ daily), theophylline ( 0.2 or $0.4 \mathrm{~g}$ daily) or sertraline hydrochloride ( $50 \mathrm{mg}$ daily) to the initially assigned therapy. After therapy modification, 26 tests were performed again (TET2 and TET3), and their data were included for another analysis of recurrence. In those patients whose therapy was modified but no other TET performed, the event occurring before drug therapy modification was regarded as the final one (Fig. 1).

The mean follow-up period was $19 \pm 15$ months (median 17 months).

Data analysis: in patients with a negative TET and in those with a persistently positive test, the correlation between drug efficacy and negative UTT was assessed by analysis of probability of recurrence using the KaplanMeier actuarial method ${ }^{24}$.

Results were compared with the log-rank test. A $P$ value $<0.05$ was considered statistically significant.

\section{Results}

Negative UTTs were observed in $37(66 \%)$ patients after the initial therapy (TET1), whereas the test remained positive in 19 (34\%).

When all 82 TET results were collectively analyzed (TET1, TET2, TET3), 43 (52\%) were negative and 31 (38\%) remained positive. In $8(10 \%)$ patients, postural orthostatic tachycardia syndrome (POTS - defined as an increase in heart rate of more than $30 \mathrm{bpm}$ in the upright position when compared with baseline values, associated with symptoms of orthostatic intolerance) was observed.

The correlation between symptom recurrence and UTT results obtained by Kaplan-Meier actuarial analysis is shown in Figure 2. TableIdemonstrates that after a 6-month follow-up, the probability of symptom recurrence was $2 \%$ for patients with a negative TET and $36 \%$ for those with positive tests. After a 1year follow-up, $52 \%$ of the patients showing positive tests experienced a recurrence of symptoms, whereas $95 \%$ of the negative UTT patients were asymptomatic. All patients with POTS had a recurrence of symptoms.

Only 13 patients (16\%) experienced syncope spells (1.64 \pm 0.93 episodes, median of 1 episode) after starting drug therapy. Most patients that remained symptomatic experienced near-syncope.

\section{Discussion}

The present study consists of severely symptomatic patients with neurocardiogenic syncope who received specific drug therapy. Although this disorder is generally associated with a very good prognosis, all patients included in this study had many recurrences and severe social and psychological limitations affecting their quality of life and warranting specific pharmacological therapy.

We have demonstrated a significantly lower probability of recurrence related to a negative UTT. These data suggest that in patients with severely symptomatic neurocardiogenic syncope, UTT may be an acceptable method for assessing drug therapy efficacy during a short-term follow-up.

Cox et $\mathrm{al}^{25}$, studying the correlation between treatment efficacy and UTT results in patients with neurocardiogenic syncope, observed a recurrence of symptoms in $10 \%$ of the patients with tilting-guided therapy and in $23 \%$ of empirically treated patients. When the presumably effective therapy (negative UTT) was discontinued, $42 \%$ of the patients had syncope recurrences $(P<0.0009)$. Although the authors have not mentioned the time elapsed from the onset of drug therapy to the recurrence of symptoms, their results also suggests that negative UTT may be considered a predictor of treatment efficacy.

Natale et $\mathrm{al}^{26}$ investigated potential variables related 


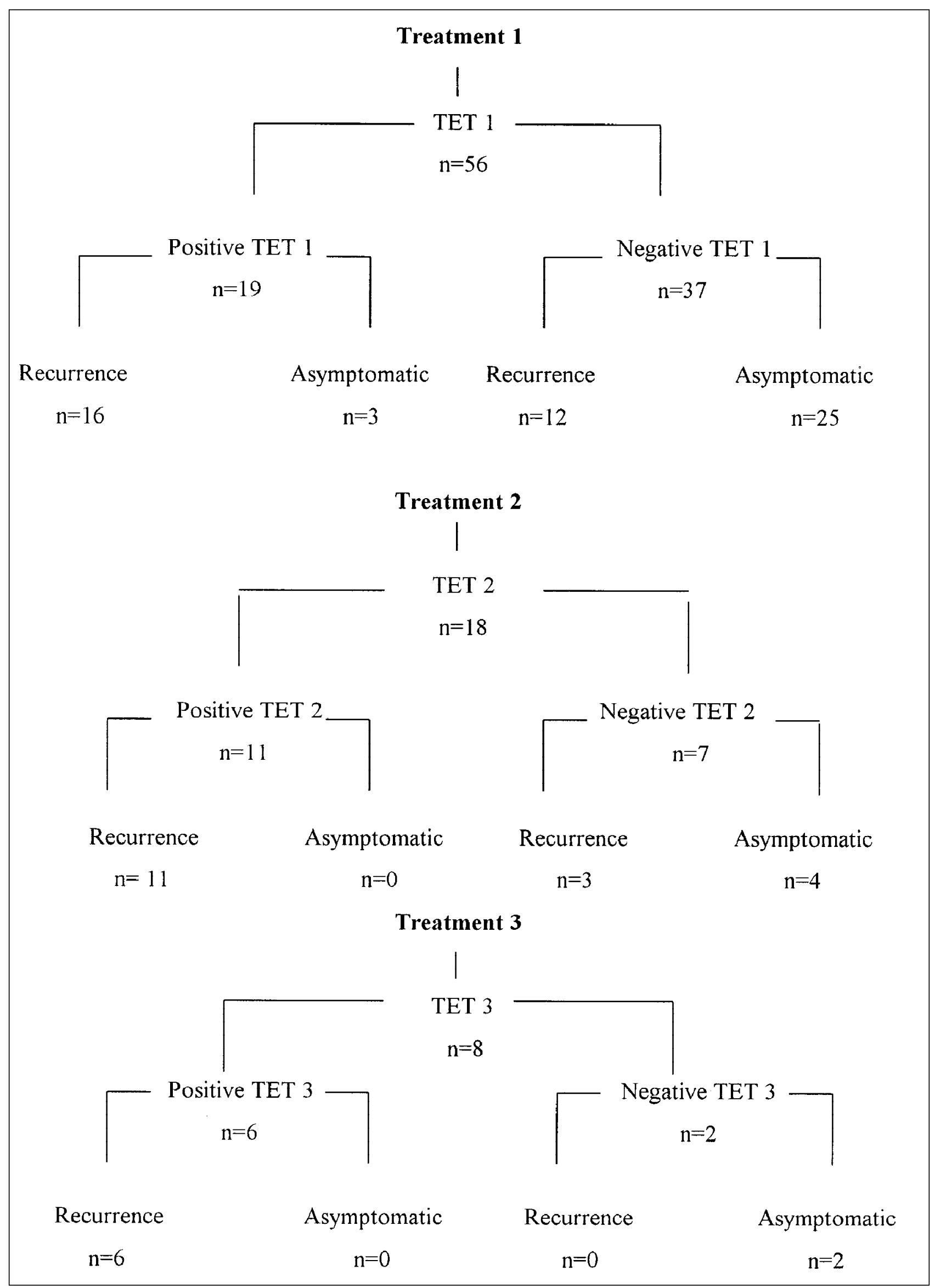

Fig. 1 - Study design. 


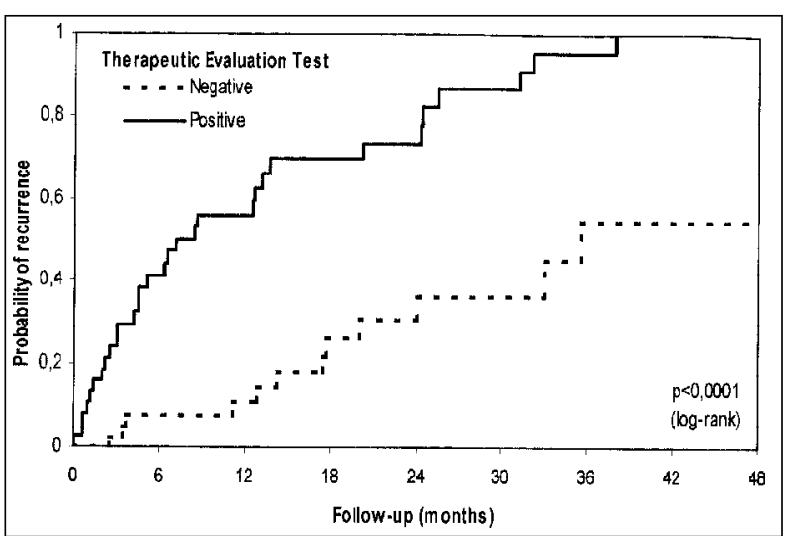

Fig. 2 - Kaplan-Meier curves of probability of recurrence and upright-tilt result after therapy.

\begin{tabular}{|l|c|}
\hline \multicolumn{2}{|c|}{ Table I - Probability of recurrence and the upright-tilt testing result } \\
after therapy.
\end{tabular}

to efficacy of treatment with $\beta$-blockers in patients with neurocardiogenic syncope. They concluded that negative UTT after esmolol was a good predictor of oral metoprolol efficacy $(P<0.0001)$. In another study, to assess the efficacy of different drugs for neurocardiogenic syncope, Natale et $\mathrm{al}^{27}$ observed that $6 \%$ of the patients who received tiltingguided therapy experienced a recurrence. Thirty-six percent of the patients in the empirical therapy group had recurrences, whereas $67 \%$ of the patients without treatment remained symptomatic during follow-up $(P<0.01)$. This study clearly shows the distinct clinical behavior of the 3 groups of patients. Their study design was different from ours because serial tilt-table tests were used for drug therapy selection in 1 of the groups, and for the remaining 2 groups a second UTT was not performed, so it is not clear how many of these patients would have a negative result in a second test. Nonetheless, the group empirically treated and not treated had a significantly higher recurrence rate.

We also observed, in our series, that recurrence of syncope spells were low (16\%), despite of the large number of patients presenting with presyncope, suggesting a general improvement in symptoms. On the other hand, $9(70 \%)$ of the 13 patients who experienced syncope after treatment had had a positive TET.

Sheldon et al ${ }^{28}$ questioned the value of a positive UTT for predicting syncope and near-syncope. They showed that a decrease in syncope recurrence is expected after a positive UTT (from 0.3 to 0.03 episodes a month) in the absence of medication. Brignole et al ${ }^{29}$ also suggested that, after a positive test, a trend occurs toward spontaneous remission of symptoms over time, independently of the use of placebo or tilting-guided therapy. They reported that, although a marked difference occurred in the frequency of negative tests between the placebo group and those assigned to medical therapy, clinical behavior during the follow-up was similar in both groups. The explanation for that is the wellknown placebo effect observed in patients with neurocardiogenic syncope, a disorder clearly related to anxiety states. Recognizing precipitating factors and prodromic symptoms to take clinical preventive measures certainly influences patient outcome. However, in that study, recurrences were observed earlier in the placebo group.

In our study, after 48 months of follow-up, all patients with positive TET had recurrences, $52 \%$ occurring during the first year. However, a large long-term recurrence rate occurred in patients with a negative TET. A marked difference between the probability of recurrence in patients with a negative and positive TET persisted over time, but a significant increase occurred in recurrence rates in both groups during long-term follow-up.

Because the prognosis of neurocardiogenic syncope is highly favorable, medical therapy is mainly recommended to improve quality of life. However, frequent recurrences carry arisk of physical trauma, car accidents, and social and psychological distress, along with the need for health assistance.

Concluding, the present study demonstrated a good correlation between the acute (negative UTT) and chronic efficacy (symptom-free) of drug therapy for neurocardiogenic syncope, so that serial UTT should be indicated for severely symptomatic patients with neurocardiogenic syncope, in order to guide therapy.

\section{References}

1. Lurie K, Benditt D. Syncope and the autonomic nervous system. J Cardiovasc Electrophysiol 1996; 7: 760-76.

2. Linzer M, Gold DT, Pontinen M, Divine GW, Felder A, Brooks WB. Recurrent syncope as a chronic disease. J Gen Intern Med 1994; 9: 181-6.

3. Linzer M, Pontinen M, Gold DT, Divine GW, Felder A, Brooks WB. Impairment of physical and psychosocial function in recurrent syncope. J Clin Epidemiol 1991; 44: 1037-43
4. Linzer M, Varia I, Pontnen M, Divine GW, Grubb BP. Medically unexplained syncope: relationship to psychiatric illness. Am J Med 1992; 92: 18S-25S.

5. Grubb B. Neurocardiogenic syncope. In: Grubb B, Olshansky B, editors. Syncope: Mechanisms and Management. $1^{\text {st }}$ ed. Armonk: Futura Publishing Co., 1998: 73-106.

6. Benditt DG, Lurie K, Adler WS, Sakaguchi S, Schultz J. Pathophysiology of vasovagal syncope. In: Blanc JJ, Benditt D, Sutton R, editors. Neurally Mediated 
Syncope: Pathophysiology, Investigation and Treatment. $1^{\text {st }}$ ed. Armonk: Futura Publishing Co., 1996: 1-24

7. Kapoor WN. An overview of the evaluations and management of syncope. In: Grubb B, Olshansky B, editors. Syncope: Mechanisms and Management. $1^{\text {st }}$ ed. Armonk: Futura Publishing Co., 1998: 1-13.

8. Kenny RA, Ingram A, Bayless J, Sutton R. Head up tilt: a useful test for investigation of unexplained syncope. Lancet 1986; 1: 1352-5.

9. Kapoor W. Importance of neurocardiogenic causes on the etiology of syncope. In: Blanc JJ, Benditt D, Sutton R, eds. Neurally Mediated Syncope: Pathophysiology, Investigations and Treatment. $1^{\text {st }}$ ed. Armonk: Futura Publishing Co., 1996: 55-62.

10. Sutton R. Vasovagal syncope: clinical features, epidemiology and natural history. In: Blanc JJ, Benditt D, Sutton R, editors. Neurally Mediated Syncope. Pathophysiology, Investigations and Treatment. $1^{\text {st }}$ ed. Armonk: Futura Publishing Co., 1996: 71-4.

11. Grubb B, Kosinski D. Tilt table testing: concepts and limitations. PACE 1997; 20: 781-7.

12. Hachul D, Sosa E, Cansolim F, et al. Valor diagnóstico do teste de inclinação na avaliação da síncope de origem indeterminada: resultados preliminares. Arq Bras Cardiol 1994; 62: 7-9.

13. Morillo CA, Klein GJ, Gersh BJ. Can serial tilt testing be used to evaluate therapy in neurally mediated syncope? Am J Cardiol 1996; 77: 521-3.

14. Brooks R, Ruskin JN, Powell AC, Newell J, Garan H, Mcgovern BA. Prospective evaluation of day-to-day reproducibility of upright tilt table testing in unexplained syncope. Am J Cardiol 1993; 71: 1289-92.

15. Kapoor W, Smith M, Miller N. Upright tilt testing in evaluating syncope: a comprehensive literature review. Am J Med 1994; 97: 78-88.

16. Benditt D, Ferguson D, Grubb B, et al. ACC Expert Consensus Document: tilt table testing for assessing syncope. J Am Coll Cardiol 1996; 28: 263-75.

17. Hachul D, Sosa E, Consolim F, et al. Reprodutibilidade do teste de inclinação em pacientes com síncope neurocardiogênica. Arq Bras Cardiol 1994; 62: 297-9.
18. Chen XC, Chen MY, Remole S, et al. Reproducibility of head up tilt table testing for eliciting susceptibility to neurally mediated syncope in patients without structural heart disease. Am J Cardiol 1992; 69: 755-60.

19. Morillo CA, Ellenbogen KA, Klein G. Head-up tilt testing: the balance of evidence. Br Heart J 1995; 73: 583-6.

20. Fish FA, Strasburger JF, Benson W. Reproducibility of a symptomatic response to upright tilt in young patients with unexplained syncope. Am J Cardiol 1992; 70: 605-9.

21. Grubb B, Wolfe D, Tenesy-Armos P, Hahn H, Elliott L. Reproducibility of head upright tilt table test results in patients with syncope. PACE 1992; 15: 1477-81.

22. Buitleir M, Grogan EW, Picone MF, Casteen JA. Immediate reproducibility of the tilt table test in adults with unexplained syncope. Am J Cardiol 1993; 71: 304-7.

23. Leor J, Rotstein Z, Vered Z, Kaplinsky E, Truman S, Eldar M. Absence of tachycardia during tilt test predicts failure of b-blocker therapy in patients with neurocardiogenic syncope. Am Heart J 1994; 127: 1539-43.

24. Armitage P, Barry B. Statistical methods in medical research. $3^{\text {rd }}$ ed. Oxford Blackwell Scientific Publications, 1994.

25. Cox MM, Perlman BA, Mayor MR, et al. Acute and long-term beta-adrenergic blockade for patients with neurocardiogenic syncope. J Am Coll Cardiol 1995; 26: $1293-8$

26. Natale A, Newby KH, Dhala A, Akhtar M, Sra J. Response to beta blockers in patients with neurocardiogenic syncope: row to predict beneficial effects. J Cardiovasc Electrophysiol 1996; 7: 1154-8.

27. Natale A, Sra J, Dhala A, et al. Efficacy of different treatment strategies for neurocardiogenic syncope. PACE 1995; 18: 655-62.

28. Sheldon R, Rose S, Flanagan P, Koshman ML, Killam S. Risk factors for syncope recurrence after a positive tilt-table test in patients with syncope. Circulation 1996; 93: 973-81.

29. Brignole M, Menozzi C, Gianfranchi L, Lolli G, Bottoni N, Oddone D. A controlled trial of acute and long-term medical therapy in tilt-induced neurally mediated syncope. Am J Cardiol 1992; 70: 339-42. 